\title{
Pierre Bourdieu, Edmond Goblot e a educação burguesa
}

\author{
Juarez L. de Carvalho Filho
}

\section{Resumo}

Este artigo propõe uma discussão sobre duas obras clássicas da sociologia contemporânea: A Barreira e o Nivel: estudo sociológico sobre a burguesia francesa moderna (1925), de Edmond Goblot ( I 858-1935) e A Distinção: crítica social do julgamento (1979), de Pierre Bourdieu ( 1930 2002), que contribuíram na França na elaboração de um quadro analítico para uma sociologia disposicional da burguesia e de uma sociologia da educação e da cultura, nos estudos da classe dirigente e o poder. Goblot coloca, antes de Bourdieu, os fundamentos de uma sociológica da distinção social. Se distanciando da concepção materialista de classes sociais, inaugura uma perspectiva cultural descrevendo etnograficamente os costumes da burguesia francesa. Bourdieu nessa perspectiva, mas de maneira mais sofisticada do ponto de vista do método, da análise sociológica e mobilizando campos próximos das ciências sociais (psicanálise, linguística, analise de correspondência...) rompe com os substancialismos de classe e a naturalização do habitus e os estilos de vida socialmente distintos. A lógica social da distinção não está nos critérios quantitativos (patrimônio), mas nas propriedades qualitativas (capital cultural, simbólico...) partilhadas por aqueles que são membros de um mesmo grupo social. Este artigo objetiva, além de identificar as afinidades destes dois trabalhos, demonstrar suas contribuições para a sociologia da educação e da cultura, notadamente para as pesquisas sobre as escolas da classe dirigente no Brasil.

Palavras-chave: Classe social. Distinção. Habitus. Sociologia da burguesia. Sociologia da educação.

\section{Introdução}

O presente artigo propóe um paralelo entre duas obras doravante clássicas da sociologia contemporânea que contribuíram para lançar as bases epistemológicas de uma sociologia disposicional da burguesia, da educação e da cultura, a saber: A Barreira e o Nivel: estudo sociológico sobre a burguesia francesa moderna (1925), de Edmond Goblot (1858-1935) e A Distinçáo: crítica social do julgamento (1979), de Pierre Bourdieu (1930-2002).

Em A Barreira e o Nivel, Goblot coloca, antes de Bourdieu, os fundamentos de uma teoria sociológica da distinção social. Se distanciando de uma

I Doutor em Sciences Sociales et Économiques pelo Institut Catholique de Paris. Professor adjunto III da Universidade Federal do Maranhão e do Programa de Pós-Graduação em Ciências Sociais da UFMA. 
análise materialista das classes sociais, uma tônica da época, ele lança luzes numa perspectiva cultural descrevendo de modo etnográfico os costumes da burguesia francesa moderna, mundo que ele conhece do interior, onde ele mesmo se inscreve socialmente. Contemporâneo de Henri Bergson e de Émile Durkheim na École normale supérieure, Edmond Goblot, filósofo da Lógica, não desfruta do mesmo prestígio intelectual dos seus contemporâneos, porém, tornou-se um autor de referência no campo da Lógica e de Filosofia das Ciências. A Barreira e o Nivel influenciou fortemente os contemporâneos do seu autor. Hoje, Goblot é considerado um precursor dos trabalhos de Bourdieu sobre a distinção (LALLEMENT, 2015, p. 282). A Distinção figura como uma obra carrefour da sociologia de Bourdieu, segundo Fréderic Lebaron, considerado "O Capital de Pierre Bourdieu". Para Lebaron, o sucesso d'A Distinção (resultado de um conjunto de pesquisas dele e de seu grupo de trabalho, obra mais lida, mais citada) se deve ao fato de ter suscitado "efeito de revelação próximo da psicanálise, uma espécie de "retorno ao recalque social". Para Lebaron A Distinção aparece como uma obra carrefour, no sentido de que ela articula ao mesmo tempo de maneira original a objetividade de regularidades estatísticas, representaçóes com o auxílio do método de analise de dados, observação "qualitativa" e, mais precisamente "discursiva" e "iconográfica” da onipresença dos determinantes sociais, a sócio-análise dos sistemas de classificação e, enfim, a "crítica" sociológica daquilo que Bourdieu chamou de postura escolástica (LEBARON, 2012, p. 155-156). Muito evidentemente reside nestes elementos a originalidade d'A Distinção em relaçáo à Barreira e o Nivel de Goblot. Enquanto a obra de Goblot se caracteriza mais como um estudo descritivo de estilo etnográfico, a de Bourdieu se apresenta com um estudo analítico dos mais sofisticados, mobilizando ferramentas teóricas e epistemológicas e propondo uma unidade das ciências sociais (antropologia, psicanálise, linguística, estatística). É comum se afirmar que Bourdieu teria se negado a citar Goblot. Esta afirmação não procede, uma vez que Bourdieu não somente tinha conhecimento da obra de Goblot, como o cita em um dos primeiros textos sobre a noçáo de classe social: Condition de classe et position de classe (2005, p. 9). 
Num primeiro momento busca-se neste texto situar Goblot (mais desconhecido que Bourdieu ${ }^{2}$ ) no campo intelectual francês e a novidade do seu ensaio sociológico sobre a burguesia francesa, notadamente no que concerne a noção de classe social rompendo com a noção materialista de Marx. O mesmo se fará para Bourdieu, uma vez que se entende que este último, buscou, n'A Distinção romper com os substancialismos de classe. Numa terceira seçáo a partir da noção de distinçáo, busca-se um paralelo entre os dois trabalhos, mostrando, o quanto possível, as diferenças existentes. Por último, enfatizar-se-á a educação burguesa e o seu papel na luta de distinção.

Conclui-se propondo, além de identificar as afinidades destes dois trabalhos (este é um dos objetivos deste texto) frequentemente ignoradas pelos leitores e estudiosos de Bourdieu (sobretudo no Brasil), demonstrar suas contribuições para uma sociologia disposicional, uma sociologia da educação e da cultura, notadamente sobre as pesquisas sociológicas relativas às escolas da classe dirigente no Brasil.

\section{Da lógica de classes}

Não se discute aqui a longa história social do conceito de classes sociais. Existem trabalhos de grande envergadura que tratam com pertinência da história e a arqueologia de um dos termos essenciais das ciências sociais e políticas $^{3}$. O interesse dessa seção é demonstrar os critérios definidos por Goblot e Bourdieu sobre o que constitui uma classe social na lógica de distinção.

Edmond Goblot nasceu em Mamers (França) em 1858 e morreu em 1935. Foi aluno da École normale superieure, contemporâneo de Émile Durkheim (1856-1917) e Henri Bergson (1859-1941). Filósofo de formação, Goblot obtém a Agrégation ${ }^{4}$ de philosophie em 1893. Consagrou sua tese de

2 Digno de nota é o fato de que o liuro de Goblot foi publicado no Brasil em 1989, enquanto que o livro $A$ Distinção foi publicado somente em 2007, embora a obra deste último comece a ser difundida no Brasil desde os anos 1970 (CARVALHO FILHO, 2015). O liuro de Goblot sofreu, no entanto, uma modificação no título: $A$ Barreira e o Nivel: retrato da burguesia francesa na passagem do século. Trad. De Estela dos Santos Abreu e Maria da Silva Cravo. São Paulo: Papirus, 1989.

3 Cf. por exemplo, de PIGUET, Marie-France. Classe: histoire du mot et genèse du concept des physiocrates aux historiens de la restauration (1996).

4 Concurso público para atuar como professor do Liceu ou de faculdade e que confere aos aprovados o título de professor "agrégé". 
doutorado sobre a filosofia das ciências (Le système des sciences), ficou primeiramente mais conhecido como filósofo da Lógica (Traité de logique, 1902; La logique des jugements de valeurs, 1913), sendo seu Traité de logique, por muitos anos, adotado nos estudos de filosofia como referência. Goblot foi professor no liceu de Bastia (Córsega) e na faculté de lettres de Caen e de Lyon. No entanto, Goblot ficou celebrizado na França após a publicação, em 1925, do livro La barrière et le niveau: étude sociologique de la bourgeoisie française moderne, que se tornou um clássico da sociologia contemporânea na França. Mas desde 1899, Goblot se interessa ao problema que se tornará o centro da nova sociologia, e publica, neste ano, na Revue d'économie politique, um artigo Les classes de la société, demonstrando que $A$ barreira e o nivel, náo foi um acaso (LALLEMENT, 2015).

Antes de discutir elementos constitutivos do clássico de Goblot e d'A Distinçáo de Bourdieu, cabe aqui enfatizar a ruptura estabelecida frente ao conceito de classe social operada pelos dois autores. Para o filósofo da lógica, a tese que dá título à sua obra está anunciada desde o primeiro capítulo, intitulado "Ideia de classe social" oposta à ideia de casta:

uma casta é algo fechado: nela se nasce, nela se morre; salvo raras exceções, nela ninguém entra, dela ninguém sai. Uma classe é algo aberto: temos os parvenus e os "rebaixados" (déclassés) [...] (p. II) As características que separam devem ser qualitativas. Além disso, são comuns a todos os que elas distinguem. Toda demarcação social é ao mesmo tempo barreira e nivel. É preciso que a fronteira seja escarpa, mas que acima da escarpa haja um planalto. Dentro de si toda classe é igualitária; não admite declives nem cumes: a igualdade na classe é condição da superioridade de classe (p. 19-20).

Vê-se a partir desses elementos de definição que para Goblot, a noção de classe social não repousa sobre os critérios quantitativos como o patrimônio, terra, máquinas, mas sobre as propriedades qualitativas compartilhadas por aqueles que são membros (nivel), mas que os distingue das outras classes sociais (barreira): as vestimentas, a moda, a educação, a linguagem, o lazer, o diploma. No capítulo "Classe e riqueza", Goblot observou também, contra a ideia marxista de "classe proprietária", que o critério de riqueza é insuficiente e artificial para demarcar as classes sociais. Argumentando que o critério pertinente é antes de tudo "como usar a riqueza" (p. 33), Goblot mostra que "distinçáo de classe é uma questão de julgamento de valor" (p. 26), de 
"representações e imagens" que passam através de práticas sociais específicas e distintamente codificadas 5 .

Para Pierre Bourdieu, a noção de classe social é um instrumento de análise teórica constituída pelo sociólogo que deve funcionar como princípio de classificação tendo um papel explicativo ${ }^{6}$ e não somente descritivo como as taxinomias das ciências da natureza. Ele distingue a classe teoricamente construída da classe real (grupo mobilizado construído dentro da realidade). O que Bourdieu propóe com essa perspectiva é a não reificação das classes sociais. Ele adota uma oposição entre substância e relação, a partir da filosofia neokantiana de Ernst Cassirer propondo uma concepção relacional e não substancial das classes sociais que náo são classes no sentido de Marx: "classe como grupo mobilizado em vista de objetivos comuns e em particular, contra uma outra classe” (BOURDIEU, 1994, p. 26). Para Bourdieu "as classes reais são produto de classificaçóes e, sobretudo, o desfecho de "luta de classificaçáo", com luta propriamente simbólica (e política) para impor uma visão do mundo social, ou melhor, uma maneira de construí-la” (BOURDIEU, 1994, p. 27).

5 Michel Lallement $(2015, p$. 16) relembra que no momento em que Goblot reflete, trabalha e escreve sobre a burguesia, outros autores fazem o mesmo. Em 1914. P. Coudert publicou La Bourgeoisie et la question sociale. Essai pour la formation d'une conscience de classe. Após a Primeira Guerra mundial, em 1924. Abel Hermant Le Bourgeois et René Johannet, L'Éloge du bourgeois français. Acentuamos aqui por ser mais conhecido o trabalho de Werner Sombart, uma das figuras mais influentes da escola de economia histórica da Alemanha, que publicou em 1913 Le Bourgeois: contribution à l'histoire morale et intellectuelle de l'homme économique moderne, publicado em francês pela primeira vez em 1926 (após a publicação de A Barreira e o Nível, 1925). Neste clássico, Sombart analisa a burguesia como um resultado da união entre um fenômeno da "psicologia histórica" e dos fatos econômicos propriamente ditos. Esta análise se separa do pensamento liberal como das ideias marxistas. Como Bernard Groethuysen, francês de origem alemã, o burguês representa após a análise de Sombart, "o homem do nosso tempo". "O burguês é a forma mais típica do espírito de nosso tempo". "O burguês não é apenas um tipo econômico, mas um tipo social e psicológico".

6 Para um aprofundamento maior sobre a teoria da classe social na arquitetura da obra de Bourdieu, o leitor pode se remeter ao artigo de Loïc Wacquant, Poder simbólico e fabricação de grupos: como Bourdieu reformula a questão das classes (20 I3). Esse discipulo de Bourdieu enfatiza que " $A$ abordagem que Bourdieu faz de classe incorpora sua concepção marcadamente relacional da vida social. Para o autor de $A$ distinção, da mesma forma que para Marx e Durkheim, o estofo da realidade social - e, portanto, a base para a heterogeneidade $e$ a desigualdade - consiste de relações. Não de indivíduos ou grupos, que povoam nosso horizonte mundano, mas sim de redes de laços materiais e simbólicos, que constituem o objeto adequado da análise social. Essas relações existem sob duas formas principais: primeiramente, reificadas como conjuntos de posições objetivas que as pessoas ocupam (instituições ou "campos") e que, externamente, determinam a percepção e a ação; $e$ e, em segundo lugar, depositadas dentro de corpos individuais, na forma de esquemas mentais de percepção e apreciação (cuja articulação, em camadas, compõe o "habitus"), através dos quais nós experimentamos internamente e construimos ativamente o mundo vivido" (WACQUANT, 2013, p. 88). 
Já no artigo publicado em 1966, Condition de classe et position de classe, (BOURDIEU, 2005) as noçôes de condição e de posição de classe permitem descrever uma situação ecológica e numérica: camponês, citadina, uma situação de renda e de status. Bourdieu neste artigo se refere a diferentes autores: a noção de status é tomada emprestada de Max Weber; a noção de "estilo de vida" vem de Groethuysen e das teorias da cultura e da relação entre linguagem e cultura; por fim, a noção de função social, de Durkheim. Esses empréstimos permitem de uma parte, descrever o que um determinado grupo em determinadas condiçóes faz destas condiçóes; permitem objetivar as razóes de suas escolhas, essas escolhas implicando uma opção que se traduz estatisticamente por uma posição sobre uma curva linear; de outra parte essas noçóes enfatizam as homologias de posiçáo que constituem uma estrutura geral. Por exemplo, as classes médias, por suas condiçóes na França escolhem uma escala de status, uma curva de posiçóes ascendente que "se define fundamentalmente por aquilo que não é mais e pelo que ainda não é, extrai inúmeras atitudes (estilo de vida: economia, trabalho), tal como sua inclinaçáo para o objetivismo, de uma posição de dupla oposição, em relação às classes superiores e em relação às classes populares" (BOURDIEU, 2005, p. 9). "Dupla posição" aos valores linguísticos que opóe o distinto ao vulgar. $\mathrm{O}$ conjunto constitui uma estrutura ao mesmo tempo econômica, cultural e linguística, historicamente determinada e geral. É, nesse sentido, que se definem aquilo que Bourdieu chamou de "herdeiros", aqueles que, desde o nascimento, acedem aos sinais de distinção (cultura livre, por exemplo). Os herdeiros são ao mesmo tempo aqueles que economicamente são, senão os mais favorecidos, ao menos os mais livres para escolher as profissóes liberais. Socialmente são os que dominam o sistema escolar (pelo número e a posição que ocupam no espaço social); e, linguisticamente sáo os que se beneficiam da familiaridade com a cultura erudita (BOURDIEU, 2004, p. 30-34).

\section{A lógica de distinção: 0 corpo como marcador social ${ }^{7}$}

Edmond Goblot abre o capítulo IV d'A Barreira e o Nivel dedicado à moda com seguinte frase: "O que diferencia o burguês é a "distinção"

7 Alguns elementos desta seção foram apresentados no seminário sobre os 30 anos de publicação d'A Distinção (1979), organizado pelo Laboratório de Leitura e Pesquisa em Sociologia da Educação de Pierre Bourdieu, coordenado pelo Prof. Dr. Antonio Paulino de Sousa (UFMA; PPGE; PPGCSoc.), em dezembro de 20 I0. Na ocasião apresentei uma comunicação intitulada "Pierre Bourdieu e A Distinção: o habitus e o corpo nas diferenciações sociais". 
(GOBLOT, 1989, p. 51) ${ }^{8}$. Utilizando o Grand Littré, Dictionnaire de la Langue Française, d'Émile Littré, Goblot destaca que numa das acepções, distinção é "aquilo que, no traje, tem um caráter de elegância, de nobreza, de bom tom. Ter distinção, um ar de distinção. A "distinção de maneiras". Em seguida Goblot completa:

não é por beleza, é para não ser confundida que a burguesia moderna se esforça para distinguir no vestuário, nos modos, na linguagem, nos objetos que a cercam. O contrário de distinto é "comum": comum é o que não distingue, vulgar é o que distingue negativamente e revela inferioridade. Esse sentido parece recente, pois não se encontra nos autores antigos (GOBLOT, 1989, p. 52).

Como se vê, a distinção é apresentada como uma separação, uma distância social, tanto material e espacial, como simbólica:

O espírito burguês tenta evitar ao máximo a promiscuidade ou qualquer aproximação; quer conservar as classes populares à distância, não se deixa invadir nem confundir; dispõe de restaurantes, hotéis (...) aos quais essas classes não têm acesso; frequentam festas em que a sociedade não é "misturada” (GOBLOT, 1989, p. 51)

N'A Distinção Bourdieu descreve uma nova cartografia dos grupos sociais no seu espaço social. Estes são notadamente ordenados segundo seu estilo de vida, para os quais Bourdieu estabelece uma classificação a partir da mobília dos apartamentos, dos costumes em termos de música e de vestimentas. Nessa démarche, os agentes são diferenciados segundo a similitude do desenvolvimento do seu apartamento, das forças de suas atividades de lazer ou dos suas preferências culturais (CARVALHO FILHO, 2013).

Como percebemos nessa sequência, o estilo de vida descrito por Goblot encontra eco nas análises de Bourdieu na relaçáo estreita entre o estilo de vida e o corpo legitimo. O estilo de vida é um conjunto de gostos, de práticas sistemáticas características de uma classe ou de uma determinada fração de classe. Ele compreende e engloba a totalidade de práticas e de obras de um agente, incluindo as práticas sexuais, as opinióes políticas, as crenças filosóficas, as

8 É importante lembrar que bem antes de Goblot, Georg Simmel se interessa ao fenômeno da moda (Philosophie de la mode, publicado em alemão em 1905), dotando-o de um caráter social distintivo, permitindo as classes superiores se misturar sem se confundir. Nessa perspectiva a moda é para ele um fenômeno social indissociavelmente vinculado a um sistema de pensamento classificatório fundado na divisão social de classe. 
convicçóes morais, as preferências estéticas (ACCARDO, 2006, p. 167-168). Essas aquisições, determinaçôes sociais, estão inscritas no nosso corpo, nas posturas, nos nossos movimentos, na nossa relaçáo ao corpo ou ao hexis corporal. O corpo, socialmente construído, é um revelador das lógicas e lutas de distinção?.

O hexis corporal é constituído de um conjunto de condutas, mais incorporadas do que interiorizadas; essas condutas tornam-se disposiçóes duráveis. A outra dimensão do habitus, nomeada por Bourdieu como ethos concerne as disposiçóes éticas. Uma e outra se reforçam. Os estudos sobre a alta burguesia (sociologia da burguesia) atestam como a elegância é menos ligada a certas vestes do que às "boas maneiras" corporais. Essas "boas maneiras" remetem às técnicas corporais e de um savoir-faire próprios à sociedade mundana (saber andar de forma leve, mas segura, andar de cabeça erguida, mas descontraída) fundado num perfeito domínio corporal. "Ter classe”, como se diz, é mostrar pelo corpo que fazemos parte de uma certa elite. A démarche, em particular constitui um verdadeiro cartão de visita: mesmo num terno, se reconhecerá o homem da periferia, de classe popular, o camponês. As condiçóes para ser elegante, distinto, devem ser perfeitamente incorporadas para parecer "quase natural" (DURET; RUSSEL, 2003, p. 14-15).

Para Bourdieu, a percepção das hierarquias sociais remete à imediata percepçáo da postura corporal. A dignidade da pessoa se expressa por seu porte e sua retidão. A classificaçáo do alto e do baixo do mundo social, se conjuga por sua oposição entre "o reto" e o "curvo". No Le sens pratique publicado em 1980 (2005, p. 119) e retomado em La domination masculine em 1998 (p. 15-16), Bourdieu evoca a divisão do trabalho entre os sexos e a divisão do trabalho sexual a partir do exemplo da "colheita de oliva" feita pelas mulheres. $\mathrm{O}$ trabalho corporal do homem, reto, se opóe à mulher curvada apanhando (com submissão) as olivas que o homem derrubou. Essa etnografia econômica

9 Nota-se aqui que Marcel Mauss inaugura essa perspectiva em "techniques du corps" (1936) concebendo essas últimas como sendo essencialmente sociais e culturais: maneira de andar, de correr, de dormir, de comer, de falar, os gestos, dependem de aprendizagens sociais. As técnicas corporais funcionam como marcadores sociais. Para Norbert Elias, por sua vez, um processo histórico de uma "longa duração", como dizia Braudel, modificou profundamente a relação dos indivíduos com o corpo. Essa "civilisation de moeurs" se caracteriza pelo crescimento do autocontrole das pulsões. Isso posto podemos afirmar no entanto, que devemos a Pierre Bourdieu e a Luc Bolstanski, o desenvolvimento, a teorização e a ilustração da importância dos usos sociais do corpo e de os ter articulado ao sistema geral do habitus (DETREZ, p. I43-144). Para Luc Boltanski (197I), Cf. Les usages sociaux du corps. 
dos camponeses nas montanhas de Kabyle confirma a estruturação da divisão do trabalho social entre os gêneros masculino e feminino, pela oposição binária entre: o alto/o baixo, reto/curvo, frente/trás.

Para Bourdieu, os agentes incorporam os habitus (no plural) que por sua vez incidem sobre a maneira pela qual eles percebem, mantêm e utilizam socialmente o corpo, situando-o no espaço social das práticas sociais e culturais. Convêm, no entanto, falar de corpo como uma categoria de percepçáo do mundo e de diferenciaçáo social, ou seja, analisar o corpo como um "marcador social por excelência", como um "capital corporal". É nesses termos que devemos falar como Bourdieu o faz n’A Distinção. Para ele, se o corpo é o lugar da denegação do social, essa denegaçáo em si, não pode ser tomada ao pé da letra; é preciso, ao contrário, desvelar o que ela esconde, quer dizer, as funçóes sociais do corpo como instrumento de classe e de classificação e de reprodução distinguindo o gosto (alimentar, estético, musical, literário, esportivo, vestuário), e o pertencimento a um habitus de classe social. Opondo-se à naturalização e à neutralidade do corpo, Bourdieu desvela n'A Distinção, o papel social do habitus enquanto forma incorporada da condição e posição de classe nos julgamentos sociais e morais remetidos sobre o corpo tanto do ponto de vista da estética, dos cuidados (de saúde) com o corpo, como da alimentação (1996, p. 210-212). Assim, o corpo é um elemento central do sistema de disposiçóes duráveis. O corpo é certamente um fator de permanência da "identidade" (que diz "eu sou") assegurando a continuidade do ser para si e para os outros, mas podemos colocar em xeque sua incapacidade a estabelecer as relaçóes sociais fora do esquema pré-construído pelos habitus.

No artigo publicado em 1977 em Actes de la Recherches en Sciences Sociales, intitulado "Remarques provisoires sur la perception sociale du corps", contém uma matriz que será desenvolvida n'A Distinção. Neste artigo Bourdieu postula que

para compreender os investimentos (em duplo sentido) do qual o corpo é objeto (custo em tempo, energia e em dinheiro como estratégia destinada a transformar o corpo, para aproximá-lo da conformação tida como legítima, maquiagem ou roupas, dietética ou cirurgia estética, para lhe tornar apresentável ou representável) é preciso relembrar algumas proposições que geralmente esquecemos por força da evidência. O corpo, como categoria de percepção e perceptível que causa impressão (o que a linguagem comum chama de físico), é de todas as manifestações do indivíduo, a que menos se deixa modificar apesar do 
investimento de ordem variada. O corpo deve ser levado em consideração por significar de forma mais adequada a natureza de uma pessoa, funcionando, portanto como uma forma de linguagem de identidade social em que "se é falado, mais do que se fala". No corpo se leria a linguagem da natureza cultivada em que se trai o mais escondido e o mais verdadeiro, já que o menos conscientemente controlado e controlável e que contamina e determina as mensagens percebidas e despercebidas de todas as expressões, começando pela fala (BOURDIEU, 1977, p.5I).

O corpo como construto social é, portanto, um princípio central na permanência da "identidade". Ele articula a dimensão tanto do indivíduo como da coletividade. É nesse sentido que o habitus precisa do corpo para se tornar ser; mas, sem se tornar pré-estabelecido do habitus, o corpo não é.

Para Bourdieu (1977, p. 51-520), é necessário compreender os investimentos no qual o corpo é objeto: maquiagem, cirurgia estética. $\mathrm{O}$ corpo não é algo que portamos, é locus de categorias, frutos da disposição do habitus. No corpo, há uma linguagem que transmite tudo aquilo que se é. É a linguagem social. O corpo é um produto social: as deformaçóes, as doenças, o gosto, a cultura são informaçóes que podem ser transmitidas pela maneira de se portar. São sinais distintivos que constituem o corpo e que são produtos de uma fabricação. Expressam uma naturalidade, mas são socialmente cultivados.

Mas, segundo Bourdieu, essa linguagem da identidade natural, socialmente cultivada, é em efeito, uma linguagem da identidade social, assim naturalizada (sob forma de exemplo vulgar ou de distinção "natural", logo legitimada). Bourdieu lembra que o corpo "naquilo que ele tem de mais natural em aparência, quer dizer nas dimensóes de sua conformação visível (volume, tamanho, peso, etc.) é um produto do social". E desse feito ele com suas propriedades socialmente construídas e socialmente naturalizada, funciona como um princípio de classificação social um vez que "a distribuição desigual entre as classes das propriedades corporais”, assim como as diferentes espécies de capital (econômico, cultural, social, simbólico) são mal e desigualmente repartidas, "se cumprem através de diferentes mediaçóes tais como as condiçóes objetivas de condiçóes de trabalho (com as deformaçóes, doenças, mutilação) e os costumes em matéria de consumo, que enquanto dimensão de gosto, ou seja, de habitus, podem se perpetuar para além das condiçóes sociais de produção". É por isso, que o corpo, segundo Bourdieu, não designa somente a posição atual no mundo social, mas também sua trajetória social e histórica. Desse 
fato, as diferenças de pura conformação física, são redobradas pelas diferenças de hexis, de postura, diferenças na postura corporal, na maneira de portar e de se comportar, onde se expressa na relação do corpo ao mundo social.

A representação social do corpo, com o qual cada agente deve contar, desde a origem, para elaborar sua representação subjetiva de seu corpo (seu hexis corporal), é obtida pela aplicação de um sistema de classificação social cujo princípio é o mesmo dos produtos sociais ao qual ele se aplica. Assim o corpo teria todas as chances de receber um preço estritamente proporcional à posição de possuidores na estrutura de distribuição das outras propriedades fundamentais.

\section{Educação burguesa}

Sem dúvida a educação exerce um papel fundamenta na lógica de distinção, contribuindo na estruturação de práticas sociais e culturais distintivas e codificadas. Podemos nos remeter ao clássico de Thorstein Veblen Teoria da classe ociosa (1899) quando Goblot faz referência à necessidade de não trabalhar. Veblen enfatizou os processos sociais de disputas entre os homens, conduzindo-os a comprometer-se nas lutas de distinção no que importa manifestar sua superioridade. Ele se interessa aos modos distintos de consumo da burguesia no final do século XIX. Neste sentido, o meio mais seguro de distinguir-se era mostrar que não se trabalhava ou mais precisamente que não havia necessidade de trabalhar para viver. Em contraste com a grande maioria que tinha a necessidade de viver do trabalho na indústria, alguns podiam contentar-se em extrair o fruto do labor dessa maioria. A riqueza extorquida permite constituir, assim, a "classe ociosa" que manifesta, de modo ostentatório, que ela não tem necessidade de trabalhar para viver. Assim, descrevendo os "ditos pertencentes à mentalidade coletiva" da burguesia, Goblot afirmava que

uma das coisas que mais denunciam a falta de recursos é a necessidade de trabalhar para viver. É mais fino a pessoa ser servida do que servir-se, ser servida do que servir os outros; é muito honroso ser proprietário, não fazer nada (...) e viver do trabalho do outro: a honra é o dinheiro (GOBLOT, 1989, p. 32).

Esse tempo livre, tempo do ócio, será o exigido nos processos de escolarização, ou seja, na aquisição de disposiçóes e de códigos da vida burguesa que passa eminentemente pela educação. Bourdieu constantemente lembrava que 
a aquisição dos instrumentos para desvelar as coisas escondidas, inconscientes ou implícitas do mundo social, exige muito tempo livre; e que o privilégio dos intelectuais (e dos artistas) é o fato de que eles têm tempo. Como dizia Platáo, skholê, significa ao mesmo numa palavra o lazer e a escola (BOURDIEU, 1997, p. 265).

\section{Goblot afirmava que}

a ordem social tem estreitas relações com as profissões e os ofícios assim como com os partidos políticos; mas nunca é a profissão ou o partido que determina a classe e sim, quase sempre, a classe que fixa as profissões e os partidos. Antes de tudo, a educação cria e mantém a distinção de classe; mas a palavra "educação" toma aqui um sentido novo e restrito: trata-se da educação que "classifica”, não da que desenvolve o mérito pessoal (GOBLOT, 1989, p. 19).

No final deste capítulo ("Classe e riqueza"), o autor avança que "viver burguesmente é, antes de tudo, proporcionar aos filhos uma educação burguesa" (GOBLOT, 1989, p. 36). Goblot descreve a educaçáo, ponto crucial da lógica de classe e de distinção, numa sequência de três capítulos: Educação moral; Educação intelectual; Educação estética. Vários temas são abordados: a polidez (simples e convencional) que se aprende de maneira tácita no seio familiar, as práticas da vida cotidiana e as influências do meio social, as práticas religiosa (aprendizagem do catecismo e a frequentaçáo à missa dominical), o uso da mentira, a emergência da prostituição, aprendizagem da música e outras práticas artística. Buscaremos enfatizar aqui mais a educação intelectual, que, consoante à educação estética, ou como diz Bourdieu, a economia dos bens simbólicos, influenciou as pesquisas no campo da educação e da cultura. Como relembra Delphine Moraldo (2010), as análises consagradas à "educação intelectual", acentuado no baccalauréat ${ }^{10}$ e a aprendizagem do latim, sáo pontos centrais que constituem a lógica da "barreira e o nivel'. Tudo isso prefigura as análises posteriores da sociologia da educação. Goblot observava, ainda, que o conhecimento do latim, era a garantia de uma "cultura de luxo" que por muito tempo funcionou como um princípio de distinção entre a burguesia e o resto da sociedade (quando o ensino se tornou obrigatório e gratuito), antes de ser substituído por uma "barreira oficial e garantia do Estado". A função do baccalauréat era de distinguir e de nivelar a elite (MORALDO, 2010).

10 Exame nacional que sanciona o curso secundário francês e serve de ingresso à universidade. 
No que concerne a estas pesquisas em sociologia da educaçáo, parece um consenso afirmar que os trabalhos de Bourdieu (os primeiros em parceria com Jean-Claude Passeron) consolidaram uma análise sociológica da hierarquização intelectual, notadamente seus livros: Les Héritiers: les étudiants et la culture; La Réproduction: éléments pour une théorie du système d'enseignement; Homo Academicus et La noblesse d'État: Grandes écoles et esprit de corps. Estes trabalhos são consagrados ao sistema escolar e às condiçóes em que as grandes escolas ${ }^{11}$ e universidades refletem os privilégios de alguns, vis-à-vis da escolaridade. Em outras palavras, como se estrutura e funciona o sistema de ensino e como certos privilégios são perpetuados e fecundados pela própria instituição. Para Bourdieu, o sistema de ensino é uma das mais importantes instituiçóes da sociedade moderna. Nesta sociedade moderna, que é a nossa, existem dois grandes princípios de dominação: o capital econômico e o capital cultural. Sobre este último, Bourdieu (1979, p. 3-4) acentua sobre as propriedades segundo ele, bizarras, no sentido de que, ele tem por propriedade de ser parcialmente incorporado; se inscreve na estrutura cognitiva, ou seja, exige um trabalho de "inculcaçáo e de assimilaçáo", custa tempo, deve ser investido pessoalmente, e tende a desaparecer, pois morre com seu portador. Por outro lado, ele não é transmitido por hereditariedade, nem diretamente sob a forma de um título de terra ou um cheque. Sua transmissão se dá de maneira a mais difusa, por um mecanismo, que passa pelo discurso, um princípio poderoso da eficácia ideológica, da própria lógica de transmissão do capital cultural. O capital cultural, segundo Bourdieu, que possui todas as espécies de propriedades se tornou, nas sociedades modernas, como os Estados Unidos e o Japão, para citar dois exemplos, um princípio da dominaçáo ao lado do capital econômico. É importante verificar, por exemplo, como demonstram Michel Pinçon e Monique Pinçon-Charlot (2007, p. 20) em suas pesquisas explorando o mundo desconhecido das aristocracias e dos grandes burgueses, que no caráter multiforme da riqueza da alta burguesia francesa, num processo cada vez mais acentuado da competição escolar, a cultura da alta sociedade não se restringe a uma erudição de amadores da arte. A escola é também um domínio onde essas famílias se distinguem. E, dado ao crescimento dos mercados

II As Grandes Escolas, na França, formam a classe dirigente, principalmente nas áreas tecnológicas e administrativas. A formação tem duração geralmente de cinco anos, após o liceu. O diploma é reconhecido pelo Estado e assegura aos portadores as melhores oportunidades de acesso aos cargos administrativos e empresariais mais prestigiosos. 
financeiros e dos riscos inerentes às novas competiçóes no mundo dos negócios, as escolas da alta burguesia, públicas e privadas, elevam o nível de exigências ao acesso às grandes escolas.

Segundo Pinçon e Pinçon-Charlot (2007, p. 84), a escola como segunda instância de socializaçáo, confronta as experiências ligadas ao meio familiar. Com efeito, os estabelecimentos de ensino que acolhem as crianças da alta sociedade apresentam a particularidade, quer sejam públicos ou privados, de assegurar, para além da instrução, propriamente dita, atividades de educação. Esses estabelecimentos transmitem os saberes indispensáveis ao sucesso nos exames nacionais, mas eles formam, ao mesmo tempo, os espíritos e os corpos legítimos dando continuidade ao trabalho educativo realizado no seio da família. Essa educaçáo burguesa assume a totalidade da personalidade das crianças, démarche em homologia com a fortuna e a multiplicidade das formas de capitais. As escolas da burguesia, como acentuam os autores, devem ainda estar à altura de assumir os elementos de socialização transmitidos pela família, todos esses códigos, maneiras de fazer e maneiras de ser que permitem de se fazer admitir como membro à parte da sociedade. No entanto eles ressaltam que, a importância da "boa" escola como lugar da transmissão da educação intelectual não se traduz apenas pelo uso exclusivo dos estabelecimentos privados, haja vista que, sendo a segregação espacial e social na região parisiense bastante acentuada, as famílias burguesas se concentram nos "beaux quartiers" para controlar os estabelecimentos públicos de ensino (laicos e republicanos) para poder enviar seus filhos com confiança (PINÇON; PINÇONCHARLOT, 2007, p. 84).

Isso colocado, podemos afirmar que pertencer à mesma categoria social náo tem o mesmo significado nos espaços escolares diferenciados para a acessibilidade, a hierarquia dos estabelecimentos escolares (socialmente marcados) e dos recursos disponíveis e mobilizáveis pelas famílias. Assim, os estabelecimentos, que não se situam em qualquer lugar no espaço geográfico e social urbano da cidade, também não recebem qualquer um, e, por isso, não têm o mesmo projeto, as mesmas opçóes diferenciadas. Em consequência disso, os grupos de elite constroem socialmente a maneira de ver o mundo, de se representar e de representar socialmente os outros no mundo social (CARVALHO FILHO, 2014). 


\section{Conclusão: a reverberação da sociologia da burguesia para pensar a educação de elite no Brasil}

Na França tanto $A$ Barreira e o Nível (Goblot), quanto $A$ Distinção (Bourdieu), contribuíram para pensar a relação das classes sociais dirigentes com a cultura e a escola. Esta última mais que a primeira. Isto é justificável pelo cursus de formação dos autores e o investimento que eles fizeram nas ciências sociais. Num recente coletivo celebrando os 30 anos de publicaçáo d'A Distinção ${ }^{12}$, toda uma parte do livro se intitula "La distinction comme théorie de classes sociales", na qual Agnés van Zanter, examina as relaçóes culturais e econômicas no interior da classe média alta a partir do estudo das disposiçóes e estratégias, associadas com a escolha dos estabelecimentos de ensino para seus filhos. Para definir essas categorias sociais ela adotou a perspectiva multidimensional do espaço social desenvolvida n'A Distinção articulando a consideração de uma hierarquização de classes e de estilo de vida. No entanto, os dois livros sáo bastante requisitados nos estudos sociológicos da nova burguesia francesa.

No Brasil, não somente $A$ Distinção, assim como o conjunto da obra de Bourdieu é mobilizado para analisar a escola e o sistema escolar, independentemente dos alcances e limites dos seus conceitos para se pensar o caso no Brasil, em razão das particularidades das realidades sociais, econômicas e culturais deste último ${ }^{13}$. Uma das frentes de difusão e circulação da obra de Bourdieu no Brasil é vinculada à sociologia da educação. O artigo "As apropriaçóes da obra de Pierre Bourdieu no campo educacional brasileiro, através de periódicos da área”, de autoria de Afrânio M. Catani, Denice Bárbara Catani e Gilson R. de M. Pereira (2001), é um levantamento que indica e busca compreender os modos de apropriaçáo que marcaram a entrada do sociólogo francês nos estudos sobre a educação e a cultura no Brasil, objetos dominantes da sociologia bourdieusiana na França, após seu retorno da Argélia como já aludido (CARVALHO FILHO, 2015, p. 9).

12 Trata-se do livro intitulado Trente ans aprés La Distintion, de Pierre Bourdieu, coordenado por Philippe Coulegeon e Julien Duval (2013).

13 Sobre essa discussão podemos consultar "A sociologia da educação de Pierre Bourdieu: limites e contribuições" de Claudio Marques Martins Nogueira e Maria Alice Nogueira (2002); "A sociologia de Pierre Bourdieu (ou como um autor se torna indispensável ao nosso regime de leituras)" (2002) e de Ana Maria Fonseca, "A noção de capital cultural é útil para se pensar o Brasil?" (2011). 
Sobre essa questão, o importante artigo de Amurabi Oliveira intitulado "La sociologie de l'éducation au Brésil: tendances historiques et contemporaines" (2013), analisa a trajetória histórica da sociologia da educação no Brasil, marcada por tensóes e rupturas, no interior das instituiçóes de ensino superior e entre os intelectuais disputando o direito legítimo para tratar de objetos concernentes às questóes educacionais. $\mathrm{O}$ autor acentua dois aspectos importantes: a centralidade da questão das desigualdades sociais na produção de sociologia da educação no Brasil e a recepção da obra do sociólogo francês neste campo de pesquisa. $\mathrm{O}$ intuito do autor náo é realizar uma revisão abrangente do trabalho feito anteriormente por outros autores, mas analisar as tendências que definem esta área de pesquisa no Brasil, dado o seu processo de formação histórica.

Nas últimas décadas o acento é colocado na escolha dos estabelecimentos de ensino. Como afirmamos noutro texto, a sociologia da escolha dos estabelecimentos de ensino desenvolvida na Europa, nos Estados Unidos e, nos últimos anos, no Brasil, encontrou eco nos trabalhos realizados sob a égide de Maria Alice Nogueira e Ana Maria F. Almeida, sociólogas expoentes da sociologia da educação, e difusoras da sociologia da educaçáo e da cultura elaborada por Pierre Bourdieu. Elas conjugam, em suas análises, a escolha do estabelecimento de ensino com o processo de socialização e de hierarquizaçáo das famílias e a escolarização das elites. Ou seja, buscam compreender e explicar a relação complexa entre família e instituição escolar (CARVALHO FILHO, 2014). No artigo "A escolha do estabelecimento de ensino pelas famílias: a ação discreta da riqueza cultural" (1998), Nogueira levanta a hipótese de que "as famílias ou diferentes meios sociais são desigualmente equipados no que se refere às condiçóes necessárias à "boa" escolha do estabelecimento escolar para seus filhos" (NOGUEIRA, 1998, p. 43). A referida autora busca verificar em que medida as estratégias de escolha do estabelecimento de ensino varia de natureza quando se passa de um meio social a outro ou de uma família a outra no interior de um mesmo universo social. Ela afirma ainda, que o que está em jogo e no centro dos discursos no campo das relaçôes entre família/escola, é a questão do grau de autonomia que pode atribuir a variável família em relação à variável social. A escolha da "boa" escola para os filhos exige um conhecimento do sistema de ensino, da situação social do estabelecimento, disposição de tempo, capital econômico e capital cultural. Ou seja, um conjunto de disposições e condiçóes objetivas, que são repartidas de maneiras desiguais entre as famílias (CARVALHO FILHO, 2014). 
A reflexão proposta aqui indica que a escola, como instituição determinante da sociedade moderna e contemporânea e a relaçáo que a classe dirigente estabelece com ela permite compreender e explicar

a contribuição concreta que o sistema de ensino oferece para a produção das diferenças de estilo de vida no mais das vezes vinculadas, na fórmula weberiana, a diferenças de status concretizadoras das fraturas sociais na medida em que presidem a constituição de redes de influências e núcleos de formação de poder estruturados por relações de amizade ou alianças matrimoniais (NOGUEIRA, 2009, p. 22).

\section{Referências}

ACCARDO, A. Introduction à une sociologie critique: lire Pierre Bourdieu. Paris: Agone, 2006.

ALMEIDA, A. M. F. As escolas dos dirigentes paulistas: ensino médio, vestibular, desigualdades sociais. Belo Horizonte: Argumentum editora, 2009.

ALMEIDA, A. M. F. A noção de capital cultural é útil para se pensar o Brasil? In: Paixão, L. P.; Zago, N. (org.). Sociologia da Educaçáo: pesquisa e realidade brasileira. 2011. Petrópolis: Vozes, 2011.

BOLTANSKI, L. Les usages sociaux du corps. In: Annales ESC, 1971. P. 205-229.

BOURDIEU, P. Remarques provisoires sur la perception sociale du corps. Actes de la recherche en sciences sociales. Vol. 14, avril 1977. Présentation et représentation du corps. p. 51-54.

BOURDIEU, P. Les trois états du capital culturel. Actes de la recherche en sciences sociales. Vol. 30, novembre 1979. L'institution scolaire. p. 3-6.

BOURDIEU, P. Le sens pratique. Paris: Les Éditions de Minuit, 1980.

BOURDIEU, P.; PASSERON, J.-C. Les héritiers: les étudiants et la culture. Paris: Minuit, 1985. BOURDIEU, P. Meditations pascaliennes. Paris: Seuil, 1997.

BOURDIEU, P. Condição de classe e posição de classe. In: BOURDIEU, P. A economia das trocas simbólicas. Trad., org. e sel. de textos, Sérgio Miceli. São Paulo: Perspectiva, 2005.

BOURDIEU, P.; PASSERON, J.-C. La réproduction: éléments pour une théorie du système d'enseignement. Paris: Minuit, 1999.

BOURDIEU, P. La Distinction: critique sociale du jugement. Paris: Editions de Minuit, 1979. BOURDIEU, P. Homo Academicus. Paris: Minuit, 1984.

BOURDIEU, P. La noblesse d'État: Grandes écoles et esprit de corps. Paris: Minuit, 1989. 
BOURDIEU, P. Raisons pratiques: sur la théorie de l'action. Paris: Seuil, 1994.

BOURDIEU, P. La Domination masculine. Paris: Seuil, 1998.

CARVALHO FILHO, J. L. de. As contribuiçóes de Pierre Bourdieu para a sociologia urbana. In: XVI Congresso Brasileiro de Sociologia, Universidade Federal da Bahia, Salvador, 2013.

CARVALHO FILHO, J. L. Segregação espacial e segregação escolar: notas para uma sociologia da distribuição geográfica e social dos estabelecimentos de ensino. Anais do IV Encontro Internacional de Ciências Sociais: Espaços Públicos, Identidades e Diferenças, de 18 a 21 de novembro de 2014 - UFPEL, Pelotas-RS-Brasil, 2014.

CARVALHO FILHO, J. L. In: de. Pierre Bourdieu : uma sociologia em movimento. In: DE SOUSA, A. P. Economia, história e teoria da prática em Bourdieu. São Paulo: Paulistana, 2015.

CATANI, Afrânio M.; CATANI, Denice Bárbara; PEREIRA, Gilson R. de M. As apropriações da obra de Pierre Bourdieu no campo educacional brasileiro, através de periódicos da área. Revista Brasileira de Educação, n. 17, p. 63-154, maio/jun./jul./ago. 2001.

CATANI, A. M. A sociologia de Pierre Bourdieu (ou como um autor se torna indispensável ao nosso regime de leituras). Educaçáo e Sociedade, Ano, XXIII, n. 78, Abril, 2002, p. 57-75.

DETREZ, C. La construction sociale du corps. Paris: Seuil, 2002.

DURET, P. ; ROUSSEL, P. Le corps et ses sociologies. Paris: Nathan, 2003.

ELIAS, N. La civilisation des moeurs. Calmann-Lévy, 1973.

GLOBOT, Edmond. La Barrière et le Niveau: étude sociologique sur la bourgeoisie française moderne. Saint-Pierre-de-Salerne: P.U.F., 1925.

GOBLOT, Edmond. A Barreira e o Nível: retrato da burguesia francesa na passagem do século. Trad. De Estela dos Santos Abreu e Maria da Silva Cravo. São Paulo : Papirus, 1989.

LALLEMENT, M. Logique de classe : Edmong Goblot, la bourgeoisie et la distinction sociale. Paris: Les Belles Lettre, 2015.

LEBARON, F. La Distinction, oeuvre-carrefour de la sociologie de Bourdieu. In: LEBARON, L. ; MAUGER, G. Lectures de Bourdieu. Paris: Ellipse, 2012.

LITTRÉ, P.-E. Dictionnaire de la langue française. Encyclopaedia Britannica France. Avril, 2001. MAUSS, M. Les technique du corps. In: MAUSS, M. Sociologie et Anthropologie. Paris: P.U.F., 1950 
MORALDO, D. Edmond Goblot, La barrière et le niveau. Etude sociologique sur la bourgeoisie française moderne. Lectures [En ligne], Les comptes rendus, 2010, mis en ligne le 30 décembre 2010, consultado em 09 setembro, 2015. URL: http://lectures.revues.org/5470.

NOGUEIRA, M. A. (org.). A escolarizaçáo das elites: um panorama internacional da pesquisa. Petrópolis: Vozes, 2003.

NOGUEIRA, Maria Alice. A escolha do estabelecimento de ensino pelas famílias: a ação discreta da riqueza cultural. Revista Brasileira de Educação, no 7, jan.-fev.-mar.-abr., 1998, p. 42-56.

NOGUEIRA, C. M.; NOGUEIRA, M. A. A. A sociologia de Pierre Bourdieu: limites e contribuiçóes. Educaçáo e Sociedade, Ano, XXIII, n. 78, Abril, p. 15-36.

PIGUET, M.-F. Classe: histoire du mot et genèse du concept des physiocrates aux historiens de la restauration. Lyon: P.U.L, 1996.

PINÇON-M.; PINÇON-CHARLOT, M. La sociologie de la bourgeoisie. Paris: La Découverte, 2007.

OLIVEIRA, Amurabi. La sociologie de l'éducation au Brésil: tendances historiques et contemporaines, Incursions n ${ }^{\circ}$, Paris, 2nd semestre 2013.

SIMMEL, G. Philosophie de la mode. Paris: Allia, 2013.

SOMBART, W. Le bourgeois: contribution à l'histoire morale et intellectuelle de l'homme économique moderne. Paris: Payot, 1966.

VEBLEN, T. Théorie de la classe de loisir. Paris: Gallimard, 1970.

WACQUANT, L. Poder simbólico e fabricação de grupos: como Bourdieu reformula a questão das classes. Trad. De Sérgio Lamarão. Novos Estudos. CEPRAP, 96, julho 2013, p. 87-103.

ZANTER, A. v. La distinction comme théorie de classes sociales. In: COULEGEON, P.; DUVAL, J. Trente ans aprés la distinction, de Pierre Bourdieu. Paris: La Découverte, "Recherches", 2013. 


\section{Pierre Bourdieu, Edmond Goblot, bourgeois and education}

\section{Abstract}

This article proposes a discussion on two classic works of contemporary sociology: The Barrier and the Level: sociological study of modern French bourgeoisie (1925), Edmond Goblot ( 18581935) and The Distinction: Social Critique of Judgment (1979) Pierre Bourdieu (1930-2002), who contributed in France in developing an analytical framework for a dispositional sociology of the bourgeoisie and the sociology of education and culture, in studies of the ruling class and power. Goblot puts before Bourdieu, the foundations of a sociological social distinction. Moving away from materialistic conception of social classes, opens a cultural perspective ethnographic describing the customs of the French bourgeoisie. Bourdieu this perspective, but in a more sophisticated manner from the point of view of the method of sociological analysis and mobilizing nearby fields of the social sciences (psychoanalysis, linguistics, correspondence analysis ...) breaks with the class substancialismos and the naturalization of habitus and socially distinct lifestyles. The social logic of distinction is not the quantitative criteria (equity), but the qualitative properties (cultural capital, symbolic ...) shared by those who are members of a social group. This article aims, in addition to identifying the affinities of these two works, demonstrate their contribution to the sociology of education and culture, notably for research on the schools of the ruling class in Brazil.

Keywords: Social class. Distinction. Habitus. Sociology of the bourgeoisie. Sociology of education. 